\title{
THE IMPORTANCE AND FORMALIZATION OF SERVICE QUALITY DIMENSIONS: A COMPARISON OF CHILE AND THE UNITED STATES
}

\author{
Rodrigo Guesalaga, Pontificia Universidad Católica de Chile, Chile
}

Dennis Pitta, University of Baltimore, United States of America

\begin{abstract}
Services account for a very large portion of the economic activity in most countries. In addition, marketing researchers have recognized a shift in companies' business orientation, from a goods-dominant logic to a service-dominant logic (Lusch and Vargo, 2006; Vargo and Lusch, 2004). Therefore, service quality becomes a critical aspect of most companies' marketing strategy. Academic research on service quality has focused mainly on determining service quality dimensions, understanding service quality antecedents, and relating service quality to key outcomes, such as customer satisfaction and performance. Still, there is limited research on how service quality perceptions differ among countries or cultures.

The purpose of this study is to compare Chile and the United States in terms of managers' perceptions of service quality across a variety of industries. Using Hofstede's dimensions of national culture and the SERVQUAL model for service quality analysis, the authors compare Chilean and US managers' perceptions of service quality in terms of the relative importance of service quality dimensions, and the degree of formalization of service quality standards. They find that reliability is the most important service quality dimension in both countries, and responsiveness is the second one. The dimensions of reliability is more important in Chile than in the US, while responsiveness is more important in the United States than in Chile. No significant differences in importance between the two countries are found for tangibles, assurance, empathy. Finally, they find that Chilean companies have more formal service quality standards than US companies in all five service quality dimensions.
\end{abstract}

References available upon request 